\title{
Recurrent Pericardial Malignant Mesothelioma
}

National Cancer Institute

\section{Source}

National Cancer Institute. Recurrent Pericardial Malignant Mesothelioma. NCI Thesaurus.

Code C9253.

The reemergence of malignant mesothelioma in the pericardium after a period of remission. 